\title{
Students Perceptions on Oral Error Correction at a Chilean High School
}

\author{
Carlos Campusano ${ }^{1 *}$, Aizan Yaacob ${ }^{2}$ \\ ${ }^{I}$ Ph.D. Student, Awang Had Salleh Graduate School of Arts and Sciences, Universiti Utara Malaysia, Sintok, \\ Malaysia \\ ${ }^{2}$ Lecturer, College of Arts and Sciences, Universiti Utara Malaysia, Sintok, Malaysia \\ *Corresponding author: campusano_cfl@ hotmail.com
}

\begin{abstract}
Given the scarce literature focusing on students' perceptions and preferences on oral error correction especially at secondary school level, this study intended to provide some insight on this important issue on English language teaching by exploring the perceptions and preferences of 149 secondary school students in Chile regarding oral error correction. An adapted version of a survey developed by Katayama (2007) was used to explore their general attitudes towards error correction and their preferences for correction of different types of errors as well as particular correction methods. Frequency distribution was calculated to analyse their Likert-scale answers. The results showed that the majority of the respondents regarded error correction as something crucial to improve their proficiency in English. They also favoured those correction techniques in which they were clearly informed about their errors or those in which they participated to correct them.
\end{abstract}

Keywords: Correction methods, Errors, Feedback, Oral error correction, Perceptions, Preferences.

\section{Introduction}

According to Ur (1996) applied linguistics usually distinguishes between errors and mistakes pointing out that errors are "consistent and based on a mis-learned generalization" whereas mistakes corresponds to "occasional and inconsistent slips" (p. 85).

Many researchers have seen mistakes as a natural part of the learning process (Brown, 1987; Ur, 1996). Ur has claimed that mistakes are just a "symptom of the learner's progress through and 'interlanguage' towards a closer and closer approximation to the target language "(p.85) In this respect, Kroll (1990) has argued that" errors to be pointed out may be those representing an individual's frequent error patterns, errors that most seriously affect communication, or stigmatizing errors" (p. 227). He has also proposed three different ways for providing oral feedback: through individual conferences between students and teachers, cassette tapes or peer response.

Feedback is usually defined as "the information that is given to the learner about his or her performance of a learning task, usually with the objective of improving this performance" (Ur, 1996, p. 242). Ur (1996) has also suggested that feedback has two main components: assessment and correction. In the first one, the student is just informed on how well or badly he/she performed in a task (e.g. grade on an exam) whereas in correction, the student is provided with specific information on his performance or some better alternatives.

There have been different views on the provision of assessments and the correction of mistakes throughout the history of language learning, many of which have changed together with the development of new language theories. When, what and how to correct students' errors are questions that experts have been trying to figure out for a long time. The phenomenon has been analysed from different perspectives and approaches in the history of second language acquisition.

In 1950's and 1960's behaviourist viewed errors as something not only inevitable but also as something that needed to be avoided and corrected immediately and comprehensively. As Brooks (1960) claimed: 'like sin error is to be avoided and its influence overcome but its presence is to be expected' (p. 8).

In the 1970's and 1980's, new ideas and approaches started to emerge and researchers started to view error correction as something unnecessary and even harmful to second language acquisition. Therefore, the support for the ideas of audiolingualism declined. One of the most respected representatives of this period was Stephen Krashen (1982) whose Monitor Model gave rise to the Natural Approach created by Terrel (1982). According to this approach, communicative competence was more important than grammatical perfection and affective factors were more important than the cognitive ones. Consequently, error correction was seen as something negative in terms of motivation.

Another approach that gained popularity during the 1980's and is still commonly used nowadays is the Communicative Approach or (CLT). With the emergence of CLT, the correction of error was not of primary importance due to its emphasis on communicative competence, meaning and fluency over the instruction of grammatical structures (Richard \& Rogers, 1986).

In the 1990's some scholars started to claim that explicit grammar instruction, error correction and focus on form could be beneficial for second language acquisition (Ellis, 1993; Long, 1996). According to Long (1996), what is not possible in 
a language or, what he called, negative evidence was crucial for the acquisition of L2. According to him, negative feedback in form of recasts received while negotiating with interlocutors could facilitate the development of L2.

As explained above, the views on oral corrective feedback and the opinions on the nature and function of feedback are diverse and are directly influenced by the different methodological perspectives, beliefs and theories of language learning. The role of correction in language teaching has been an issue of great interest for researchers and language teachers for quite some time. However, despite the fact that there is plenty of research regarding the teachers' responses to students' errors, ony a few studies have been done about the students' perceptions on error correction both in ESL and EFL settings, especially among Latin-American high school students (Oladejo, 1993; Katayama, 2007; Saeb, 2017; Salikin, 2001). In this respect, Kartchava (2016) has claimed that "to date, there is a paucity of research into learners' beliefs about specific CF techniques" (p.22). Moreover, recent studies on students' preferences on error correction have mainly focused on collegelevel students. (Abarca, 2008; Baz, 2016; Katayama 2007; Lasagabaster \& Sierra, 2005; Mohammad, 2016; Salikin, 2001, Schultz,1996, Yoshida, 2008). However, very few studies have been carried out in order to find out the perceptions of high school students.

In Chile, high school students are supposed to be the main beneficiaries of all the measures taken by the government through a program called 'English opens doors' that gradually intends to transform Chile into a bilingual country. Teacher training courses abroad, native assistants and plenty of updated audiovisual resources for teachers and students are some of the measures taken by the ministry of Education in order to improve our students' English proficiency. However, until now, the students have not been given the opportunity to share their views and opinions regarding the teaching and learning of English. Investigating their opinions regarding such an important issue on language learning provided us with valuable information which may result in better learning- teaching practices (Lyster et al., 2103; Ur, 1997).

\section{Method}

\section{A. Research Objectives}

The main objective of this study was to find out some Chilean high school students' opinions and preferences regarding the correction of oral errors in the language classroom.

Consequently, the following research questions were addressed:

1. What are the attitudes toward classroom oral error correction among some Chilean high school students?

2. What are the students' general preferences for classroom correction of different types of oral errors (e.g., pronunciation and grammar)?

3. What are the students' preferences for particular types of oral error correction methods?

\section{B. Research Design}

The specific methodology used in the study on students' perception of oral error correction in a Chilean high school was survey research design. The survey in form of questionnaire was distributed among the participants in order to find out their preferences regarding error correction.

\section{Participants}

Data was collected from a total of 149 high school students belonging to the Liceo San Agustín located in the district of El Bosque, in the southern part of Santiago in Chile. All of them were enrolled in different classes from first to fourth year of secondary school. Non-random judgmental method was used to select the school based on the criteria that the school selected would provide the information needed. However, no quota was established and random sampling was used to select the students in order to make the results of the study more credible. The school selected reflects the characteristics of most public or subsidized high schools in terms of background information of the students, school facilities and number of students per class.

In terms of language learning, each group has 4 hours of English per week. None them need to use English outside school since English is still a foreign language in Chile. These students are expected to have an ALTE 2 level of English (equivalent to a threshold user) by the end of their secondary education according to the standards defined by the Chilean government.

\section{Research Instrument}

A questionnaire developed by Katayama (2007) in his study among Japanese students was used with some minor adaptations due to the differences in the context of study. According to Katayama (2007), the questionnaire was developed based on the literature review of previous studies on error correction. The first part of the questionnaire contained personal information questions. The second section, as explained by its author, addresses research question 1 and asks the respondents about their general perceptions on error correction in the classroom. The third section dealt with the different views on error correction like when or how should learner errors be corrected and by whom. The respondents were asked to indicate their preference through a 5-point scale going from 1 (strongly disagree) to 5 (strongly agree). The third section addressed research question 2 regarding the learners' preferences for the correction of the different aspects of the language such as grammar, vocabulary, etc., indicating the frequency they wanted them to be corrected by selecting options going from never to always. In the last section, the students were asked to rank the different errors correction techniques according to a 5-point scale going from 1 to five. (1 representing no good and 5, very good). The original questionnaire was designed in English and translated to Spanish by translators from Tronwell, a language institute in Santiago with a vast experience in the translation of legal, medical and 
academic documents.

\section{E. Data Collection Procedure}

The questionnaire was sent via e-mail to the principal's assistant of the school who reproduced it and distributed it among the respondents. The answered questionnaires were sent back to the researcher via mail to be analysed.

\section{F. Data Analysis}

In order to analyse the Likert-scale answers, frequency distributions were calculated for:

1) General attitudes towards oral error correction.

2) General preferences for correction of different types of oral error.

3) General preferences for particular types of oral correction methods.

\section{Results and Discussion}

\section{A. Attitudes toward oral error correction}

1) Whether or not errors should be corrected

The students were asked if they agreed with the statement, "I want teachers to correct my errors in speaking English". 92.3\% of the respondents agreed with the statements (Table I) and the same percentage of students provided reasons explaining their choices. The reason most frequently cited for their positive attitude toward error correction was that correction helped them to improve their English and learn more.

The findings show a strong favorable attitude towards receiving error correction and. These findings are consistent with the results found in similar studies. (Abarca, 2008, Katayama, 1996, Oladejo, 1993). Students seem to see correction as fundamental to improve their language skills and seem to be aware of the necessity of being corrected. (Hayet, 2006) In this respect, Tsui (1995) claimed that teacher feedback is seen as an intrinsic part of the classroom interaction routine, so if it is not present after students' interventions, they tend to think there was something wrong with their response.

\section{2) Correcting all errors $v$. selective correction}

As observed in table I, $84.6 \%$ of the students expressed their agreement with the statement "teachers should correct all errors that learners make in speaking English". This is rather consistent with their preferences regarding the statement "teachers should correct only the errors that interfere with communication" where $64.1 \%$ disagreed with the statement. $89.7 \%$ and $87.1 \%$ of the respondents, respectively, provided reasons for these preferences. The reason most commonly mentioned was that receiving correction of all their errors would allow them to speak English properly.
The results confirmed my hypotheses regarding the Chilean students' preferences in this respect. A possible explanation for these preferences, as explained elsewhere in this paper, could be their perfectionism as language learners. Gregersen and Horwits (2002) argued that some of the characteristics of this type of learners is that they do not feel satisfied with only communicating in the target language, but they desire to speak fluently, with no grammatical or pronunciation errors and speak as a native speaker. This seems to be the case of Chilean language learners.

\section{3) Peer correction}

As regards the statement "I want my classmates to correct my oral errors in group work ", the answers were divided. While $53.8 \%$ of the respondents expressed agreement, $23 \%$ disagreed with the statement and another $23 \%$ had a neutral response. These results suggest that the majority of the respondents are willing to receive correction from their peers. $87.1 \%$ of the students offered reasons, arguing, most frequently, that peer correction was helpful and allowed them to learn cooperatively. However, we should notice that there is still an important percentage of respondents who do not have a favorable attitude towards peer correction ( $46 \%$ in total). The most frequently reasons mentioned by the respondents who favored these options were that correction was the teachers' job and that their peers are not qualified or competent enough to do it. Additionally, it is worth mentioning that the percentage of the students who showed agreement with peer correction $(53.8 \%)$ is significantly lower than the percentage of respondents that preferred teacher correction $(92.3 \%)$ as shown in table 1 . These findings are consistent with the results found in other research studies on error correction (Abarca, 2008, Hayet,2006, Katayama, 1996) According to Hayet (2006) this attitude may indicate an excessive reliance on the teacher. Abarca (2008) explained that these attitudes could be associated with certain assumptions regarding peer correction such as that feedback from peers may be wrong or that the student who is corrected could be laughed at. She has also pointed out that "the teacher is regarded as some sort of a commanding figure who has been given the right to correct learners" (p. 24).

\section{B. Types of errors students wanted to have corrected}

Section $\mathrm{C}$ of the questionnaire addressed research question 2: What are the students' general preferences for classroom error correction of different types of errors?

As can be observed in table 2, most students wanted to have their vocabulary errors $(61.5 \%)$ and grammar errors $(48.7 \%)$ corrected always. The results are in general consistent with the findings of other studies on error correction (Oladejo, 1996,

Table 1

Attitudes towards error correction

\begin{tabular}{|l|l|l|l|l|}
\hline \multicolumn{1}{|c|}{ Item } & \multicolumn{1}{|c|}{$\mathbf{N}$} & $\mathbf{1 ~ \& ~ 2 ( \% )}$ & $\mathbf{3 ( \% )}$ & $\mathbf{4 ~ \& ~ 5 ( \% )}$ \\
\hline I want teachers to correct my errors in speaking English. & 146 & $7.69 \%$ & $0 \%$ & $92.3 \%$ \\
\hline Teachers should correct all errors that learners make in speaking English. & 146 & $12.8 \%$ & $2.56 \%$ & $84.6 \%$ \\
\hline Teachers should correct only the errors that interfere with communication. & 146 & $64.1 \%$ & $17.9 \%$ & $17.9 \%$ \\
\hline I want my classmates to correct my oral errors in group work. & 146 & $23 \%$ & $23 \%$ & $53.8 \%$ \\
\hline
\end{tabular}

$1=$ strongly disagree $5=$ strongly agree 
Table 2

Types of errors students wanted to have corrected

\begin{tabular}{|l|c|l|l|l|l|l|}
\hline \multicolumn{1}{|c|}{ Item } & $\mathbf{N}$ & Never 1 (\%) & $\mathbf{2 ( \% )}$ & $\mathbf{3 ( \% )}$ & $\mathbf{4 ( \% )}$ & Always 5(\%) \\
\hline Grammar & 146 & - & - & 12.8 & 38.4 & 48.7 \\
\hline Pronunciation & 146 & 2.56 & 5.12 & 17.9 & 28.2 & 46.1 \\
\hline Vocabulary & 146 & 2.56 & - & 12.8 & 23.0 & 61.5 \\
\hline Pragmatics & 146 & 2.56 & 5.12 & 28.2 & 20.5 & 43.5 \\
\hline Discourse & 146 & - & 5.12 & 28.2 & 20.5 & 46.1 \\
\hline
\end{tabular}

Table 3

Most favored correction methods for grammar errors

\begin{tabular}{|l|l|l|l|l|}
\hline \multicolumn{1}{|c|}{ Item } & $\mathbf{N}$ & $\mathbf{1 ~ \& ~ 2 ( \% )}$ & $\mathbf{3 ( \% )}$ & $\mathbf{4 ~ \& ~ 5 ( \% )}$ \\
\hline T explains why the response is incorrect. & 146 & 0 & 10.2 & 89.7 \\
\hline T gives S a hint which might enable S to notice the error and self-correct. & 146 & 0 & 12.8 & 87.1 \\
\hline T points out that error and provides the correct response. & 146 & 7.69 & 7.69 & 84.6 \\
\hline T repeats the student's utterance up to the error and waits for self-correct. & 146 & 20.5 & 12.8 & 66.6 \\
\hline T indicates the error. & 146 & 15.3 & 17.9 & 66.6 \\
\hline
\end{tabular}

$1=$ not good $5=$ very good

Table 4

Most favored correction methods for pronunciation errors

\begin{tabular}{|c|c|c|c|c|}
\hline Item & $\mathbf{N}$ & $1 \& 2(\%)$ & $3(\%)$ & $4 \& 5(\%)$ \\
\hline T explains why the response is incorrect. & 146 & 25.6 & 25.6 & 97.4 \\
\hline T gives $\mathrm{S}$ a hint which might enable $\mathrm{S}$ to notice the error and self-correct. & 146 & 5.12 & 7.69 & 87.1 \\
\hline T points out the error and provides the correct response. & 146 & 7.69 & 7.69 & 84.6 \\
\hline $\mathrm{T}$ asks $\mathrm{S}$ to repeat the utterance. & 146 & 17.9 & 15.3 & 66.6 \\
\hline $\mathrm{T}$ indicates the error. & 146 & 15.3 & 17.9 & 66.6 \\
\hline
\end{tabular}

Katayama, 1996), although with some slight differences in the order of preference. Pronunciation and discourse errors (46.1\%, each) come after vocabulary and grammar errors in the order of priority. The pragmatics errors received the last priority for correction by the respondents as seen in table 4 . One possible explanation for these attitudes towards the correction of vocabulary and grammar errors, which according to the respondents should receive the highest attention, can lie in the teaching practices of some Chilean teachers who may still be placing a lot of emphasis on the teaching of different components such as grammar, vocabulary and pronunciation rather than the teaching of more communicative categories in which all these components could be taught in meaningful contexts. In this respect, Oladejo (1996) has pointed out that the students' preferences regarding the emphasis that should be given to each error type could be associated with the different demands on the learners.

\section{Correction methods of classroom oral errors}

The last section of the questionnaire addressed research question 3: What are the students' general preferences for particular types of error correction methods? (grammar and pronunciation errors).

\section{1) Most favored correction methods}

Table 3 shows the methods for the correction of grammar errors chosen that most students liked. The methods are listed in order of preference based on the percentages of students who gave score 4 or five to them. The most popular among the ten types of correction techniques was the one in which the teacher explains why the student's utterance is incorrect; $89.7 \%$ of the respondents preferred this correction method. The second most favored method of grammar correction method was the one in which the teacher gives the student a hint which might enable $\mathrm{him} / \mathrm{her}$ to notice the error and self-correct.87.2 \% of the respondents liked this method. The third most popular method was the one in which the teacher points out the error and provides the correct response with $84.6 \%$. of the preferences. The fourth most favored methods were the ones in which the teacher repeats the student's utterance up to the error and waits for self-correction and the one in which the teacher indicates the error. $66.6 \%$ selected both methods.

Table 4 shows the method of pronunciation correction that the majority of the students preferred. The students' most favored correction method was the one in which the teacher explains why the student's utterance is incorrect; $97.4 \%$ of the respondents endorsed this method. The second most popular technique was the one in which the teacher gives the student a hint which might enable the students to notice the error and selfcorrect; $87.1 \%$ of the students selected this technique. The third most favored method was the one in which the teacher points out the error and provides the correct response; $84.6 \%$ of the respondents endorsed this technique. The fourth most popular pronunciation error methods were the one in which the teacher asks the student to repeat the utterance and the one in which the teacher indicates the error. Both techniques received a $66.6 \%$ of endorsement.

In conclusion, most students prefer almost the same four correction methods for both grammatical and pronunciation errors and with almost the same order of preference. The results of this study are similar to the ones found in the study conducted by Katayama (1996).

The findings seem to indicate that students prefer those techniques in which errors are explicitly corrected and those that promote self-correction. Ellis (1994) argued that students tend to have a more positive attitude towards self-correction than to teacher correction. Abarca (2008) suggested that 
students tend to prefer explicit correction since they may feel afraid of not grasping the right form if they are not warned about the error or if the right model is not provided. She also argued that the students favor corrections where "they can have the opportunity to correct themselves in a more autonomous way and show that they are capable of improving their learning" ( $\mathrm{p}$. 25) In other words, learners seem to appreciate methods in which they are clearly informed about their errors and those in which they receive clear clues and guidance that can allow them to participate in the correction.

\section{Conclusion}

The results obtained showed the students' general attitudes towards error correction and their preferences for some error correction techniques presents in this study. These findings conform to the results of other cites studies on student's preferences and attitudes towards oral error correction and also confirmed my hypotheses regarding Chilean language learners. We could see that the majority of the respondents considered error correction as something crucial and necessary to improve their proficiency in the foreign language and that, in general, they disagreed with the use of selective correction preferring to have all their errors corrected. Many of them favoured those techniques in which they were clearly informed about their errors or those in which they participated in the correction. The results also showed that there is still some hesitance towards peer correction and that aspects like grammar and vocabulary are considered important by most of them.

On the basis on these findings, it might be suggested for English teachers to use and prefer clear and unambiguous correction techniques that can foster self-correction and autonomous learning.

We believe that, although these findings cannot be generalized, they offer a complementary view to previous research and provides some insights on Chilean students' attitudes and preferences towards language learning.

We suggest that another interesting area to be further investigated could be the Chilean teachers' perspectives on the topic. This information could allow us to see whether there is or not correspondence and agreement between the teachers and the students' perceptions on oral correction.

Considering the importance of matching students' expectations and teachers' practices for successful language learning (Katayama, 2007, Ur, 1996), we teachers should always be willing to find out our students preferences and opinions on language learning and adapt our teaching practices, if necessary, in order to meet our students' needs and expectations. We should be sensitive enough to hear their opinions and be aware that we can only determine which is the best and most effective way to correct their errors after we have thoroughly studied their own needs and expectations towards their learning process.

\section{References}

[1] Y. Abarca, "Learner attitudes towards error correction in a beginners English class," in Revista Comunicación, vol. 17, no. 1, pp. 18-28, July 2008.

[2] H. Baz, "Perceptions of English Instructors and Learners about Corrective Feedback," in European Journal of Foreign Language Teaching, vol. 1, no. 1, pp. 54-68, 2016.

[3] N. Brooks, "Language and Language Learning: Theory and Practice," New York: Harcourt, Brace, 1960.

[4] H. D. Brown, "Principles of Language Learning and Teaching of Foreign Languages," London: Edward Arnold Ltd., 1987.

[5] R. Ellis, "The structural syllabus and second language acquisition," in Tesol Quarterly, vol. 27, no. 1, pp. 91-113, 1993.

[6] R. Ellis, "The study of second language acquisition," Oxford: Oxford University Press., 1994.

[7] T. Gregersen, and E. Horwits, "Language learning and perfectionism: anxious and non-anxious language learners' reactions to their own oral performance, in The Modern Language Journal, vol. 86, no. 4, pp. 562570, 2002.

[8] B. Hayet, "Students' attitudes towards their errors and mistakes: The case of first year students at Batna University," Doctoral Dissertation, 2006.

[9] A. Katayam, "Japanese EFL students' preferences toward correction of classroom oral errors," in The Asian EFL Journal, vol. 9, no. 4, pp. 157166, 2007.

[10] S. Krashen, "Principles and practice in second language acquisition," 1982.

[11] B. Kroll, M. H. Long, and J. C. Richards, "Second language writing (Cambridge applied linguistics): Research insights for the classroom," Cambridge University Press, 1990.

[12] D. Lasagabaster, and J. M. Sierra, "Error correction: Students' versus teachers' perceptions," in Language awareness, vol. 14, no. 2-3, pp. 112127, 2005.

[13] R. Lyster, K. Saito, and M. Sato, "Oral corrective feedback in second language classrooms," in Language teaching, vol. 46, no. 1, pp. 1-40, 2013.

[14] M. Long, "The role of the linguistic environment in second language acquisition," in Handbook of second language acquisition, 1996.

[15] T. F. Mohammad, and T. A. Rahman, "English learners perception on lecturers' corrective feedback," in Journal of Arts and Humanities, vol. 5, no. 4, pp. 10-21, 2016.

[16] J. A. Oladejo, "Error correction in ESL: Learners' preference," in TESL Canada Journal, vol. 10, no. 2, vol. 71-89, 1993.

[17] J. C. Richards, and T. S. Rodgers, "Approaches and methods in language teaching," Cambridge University Press, 1986

[18] H. Salikin, "Learner's perception of oral error correction: An interpretive study," JIBS (Jurnal Ilmu Bahasa dan Sastra), vol. 1, no. 2, pp. 103-129, 2001.

[19] R. A. Schulz, "Focus on form in the foreign language classroom: Students' and teachers' views on error correction and the role of grammar," in Foreign Language Annals, vol. 29, no. 3, pp. 343-364, 1996.

[20] T. D. Terrell, "The natural approach to language teaching: An update," in The Modern Language Journal, vol. 66, no. 2, pp. 121-132, 1982.

[21] A. B. Tsui, "Classroom interaction. The Cambridge guide to teaching English to speakers of other languages, Cambridge University Press, pp. 120-125, 2001

[22] P. Ur, A course in language teaching: practice and theory," Cambridge University Press, 1996.

[23] R. Yoshida, "Learners' perception of corrective feedback in pair work," in Foreign Language Annals, vol. 41, no. 3, pp. 525-541, 2008. 